\title{
Reprieve for Australian research facilities
}

\section{Government backs down on threat to infrastructure funding.}

\section{Cheryl Jones}

17 March 2015

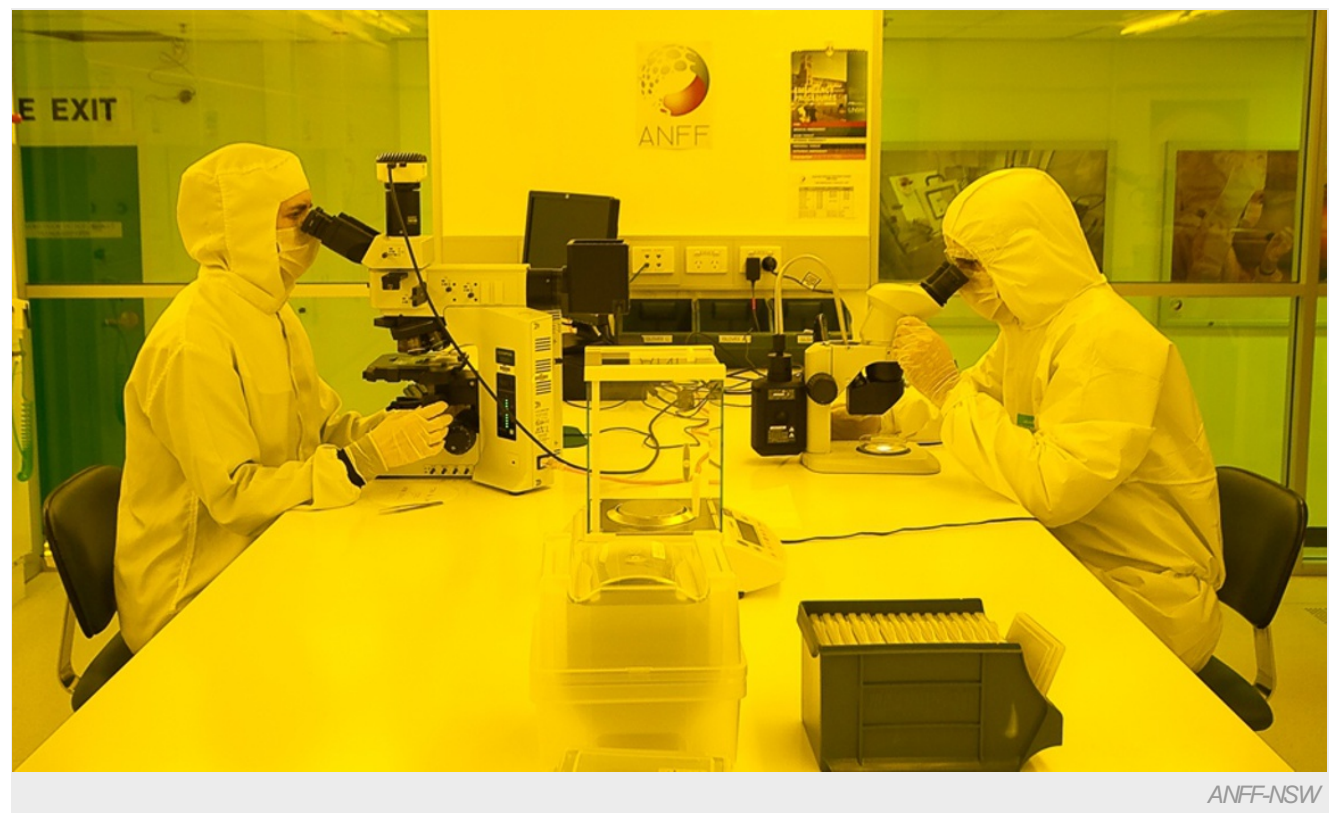

Researchers in a clean room at the University of New South Wales, Australia, one of the facilities funded through the National Collaborative Research Infrastructure Strategy.

The Australian government has bowed to pressure from the scientific community to fund key national research infrastructure that had been under threat of closure.

On 16 March, education minister Christopher Pyne told journalists that the government would pay out the Aus $\$ 150$ million (US $\$ 114$ million) it had allocated for 2015-16 to the National Collaborative Research Infrastructure Strategy (NCRIS), which covers 27 facilities employing 1,700 staff.

Pyne had previously said that the government would not be able to free up funds to support NCRIS facilities in 2015-16 unless the Australian parliament passed its controversial higher-education reform legislation. That bill was defeated in the Australian Senate on 17 March. Asked where he had found the $\$ 150$ million, Pyne said: "I found the money in offsets which will be revealed in the budget [expected on 12 May]." The government would not give up on its higher-education reform package, he added.

\section{Breathing space}

Funding for the world-class facilities, which support disciplines ranging from astronomy to materials research, had been scheduled to run out on 30 June.

Les Field, secretary of science policy at the Australian Academy of Science, told Nature that the reprieve "allows more breathing space for the scientific community and the government to try to find a more permanent solution".

"We really need a strategy to support and manage research infrastructure long term, over its whole life cycle," he said. "We can't keep going with one-year Band-Aid solutions."

But Field said that the government's decision had "limited the damage which would have happened over the next few weeks to months because some essential staff were looking elsewhere for positions with more job security".

The decision follows sustained campaigning from Australian researchers. The National Research Alliance, which includes public and private research organizations in Australia, wrote an open letter to Prime Minister Tony Abbott warning that many NCRIS facilities were 
preparing to shut down amid the funding uncertainty. The opposition (Labor Party) also campaigned hard on the issue.

Nature | doi:10.1038/nature.2015.17135 